\title{
Salivary Immunoglobulin A in Relation to the Viable Count of Mutans Streptococci in Children with Early Childhood Caries
}

\author{
Hamsa Thabit Musa, B.D.S ${ }^{1}$, Abeer M. Zwain, B.D.S., M.Sc. ${ }^{2}$, Abbas S. Al-Mizraqchi, M.Sc., Ph.D ${ }^{3}$ \\ ${ }^{1}$ MSc. student /College of Dentistry/ University of Baghdad \\ ${ }^{2}$ assistant Professor. Department of Pedodontics and Preventive Dentistry, College of Dentistry, University of Baghdad. \\ ${ }^{3}$ Professor, Department of Basic Science, College of Dentistry, University of Baghdad
}

\begin{abstract}
Introduction: Early childhood caries develops in children due to the unsuitable nocturnal feeding habit, with the presence of mutans streptococci as the caries initiating factor, competing with immunological constituent in saliva, the presence of salivary immunoglobulin A (SIgA) as an antimicrobial peptide could have a defensive role to decrease the amount of the viable count of mutans streptococci. Aims of study: this research was done to find the relations between the variables: viable count of mutans streptococci, SIgA level, dental caries index. Material and Methods: categorizing the seventy-five children (4-5) years into 3 groups (twenty-five each) mild, moderate and severe. dmfs, dmft measured according to WHO (1987), salivary Immunoglobulin A level measured by ELISA kit, viable count of mutans streptococci measured after culturing it in (Mitis Salivaris Bacitracine) agar and simple identification method. Result: the statistical analysis revealed that there was significant correlation in the viable count of MS, dmfs and dmft between (mild and moderate) and between (mild and severe). The Salivary Immunoglobulin A (mean value) showed an increase from the mild to severe as the (dmft, dmfs) increase, in which a significant correlation had been found between (mild and severe) in boys and in the total groups, a significant correlation between the viable count of MS and SIgA in the total groups. Conclusion: as the carious (tooth, surface) number increased the viable count of mutans streptococci increased indicating its role in the ECC, SIgA increased as the MS count increased indicating the induction of the immune system to produce salivary immunoglobuline A. that it has no role on the mutans streptococci.
\end{abstract}

Keywords: early childhood caries, ECC, mutans streptococci, immunoglobulin A (SIgA)

\section{Introduction}

Early childhood caries (ECC) is an infectious non-threating biofilm dependent disease affecting worldwide, the disease most frequently targets children from poor socioeconomic families and racial/ ethnic minority backgrounds, its etiology doesn't differ much from the caries process in permanent dentition [1], if neglected might affect the child social experience, attitude, general health, also it may possibly exhaust the parents finance till be treated, early diagnosis prevent its progression [2] . EAPD (European Academy of Paediatric Dentistry) uphold the early detection and prevention of the early stages of caries before cavitation [3]. According to the American Academy of Paediatric Dentistry [4] ECC definition is the "presence of one or more decayed (noncavitated or cavitated lesions), missing (due to caries), or filled tooth surfaces in any primary tooth in a 71 month of age or younger. Many nomenclatures had been used to describe the ECC like Rampant caries, Nursing caries syndrome, nursing bottle caries, Bottle mouth caries, milk bottle syndrome, baby bottle caries, and baby bottle tooth decay (these names refer to the feeding habits), labial caries, maxillary anterior caries (refer to its site), rampant infant and early childhood dental decay (refer to the age and type of decay), Severe ECC (S-ECC) [5], [6], [7], [4].

The concept of caries initiation process is the same in adult's dentition, the presence of (cariogenic bact, susceptible host, sugar, time), mutans streptococci (MS) is the considered bacteria to initiate caries with its various strains and many virulent factors competing with other bacteria and antibacterial component in saliva; surviving in a competitive environment to establish its virulence on the enamel [8]. S. mutans was detected significantly more frequently in the severe early childhood caries group than in the caries-free group in both saliva and plaque [9]. Saliva is a pure, to some extent acidic mucoserous exocrine excretion. saliva is a "complicated mixture of liquids" from the major salivay glands (two parotids, two submandibular and two sublingual) and minor salivary glands and also other sources like gingival crevicular fluid, which is (non-glandular), microorganisms, and also from the host diet, "whole saliva" is the term used to describe the non-pure fluid and separate it from the glandular secretion, Saliva have distinct role in the oral cavity in initiation or prevention of: the caries, accumulation of bacteria, entrance of foreign bacteria, virus, fungi, also in the balance between intrinsic and extrinsic factors [10], [11], [12], [13].

The antimicrobial component which is the important immunoglobulin in the salivary secretions is immunoglobulin $\mathrm{A}(\operatorname{Ig} \mathrm{A})$. The secreted form of $\operatorname{IgA}$ is called secretory $\operatorname{IgA}$ (or $\mathrm{S}-\operatorname{IgA})$. The S-IgA prevents the adherence of cariogenic bacteria to enamel [14]. In explaining complicated cariogenic phenomenon, some studies investigated a positive correlation between the viable count of mutans streptococci and the salivary immunoglobulin A level [15], [16], [17], while others revealed a negative one [18] [19] 


\section{International Journal of Science and Research (IJSR) \\ ISSN (Online): 2319-7064}

Index Copernicus Value (2015): 78.96 | Impact Factor (2015): 6.391

In Iraq, no previous researches studied the correlation between these two variables in the different stages of the ECC, and the present research was designed to find this subject.

\section{Materials and Methods}

The current study took 4 months, from December 2016 till the end of March 2017, many public and private kindergartens were visited, 200 children were investigated visually first to categorize them into the wanted groups, seventy-five children participated in the current study aged between 4-5 years the age calculated according to the last birth day [20].

Children were classified into 3 groups 25 each according to Wyne [21]. Selecting the participants from different kindergarten in Baghdad from al-karkh sector, after receiving the child guardian approval, ensuring no systemic disease, for the selected cases their BMI was measured (height and weight to determine BMI) [22] to ensure they are in the same wanted range (15-20), then the teeth of selected children were checked and their dmf was recorded according to the criteria of (WHO, 1987) [23].

The Clinical examination was conducted using the diagnostic tools (disposable mouth mirror and dental explorer, tweezer). The dental caries measurement was achieved, starting from the upper right primary second molar tooth next to the others till reaching the upper left second molar, then moving down to the lower left second molar reaching to the lower right molar. Surface tooth examination begin from the mesial, to the occlusal, distal, buccal and end with the lingual surface for all the teeth [23]. Ensuring that the child was not taking medication in the sample collection day. Saliva collection according to NAVAZESH [24], was done in the morning between $9-11 \mathrm{am}$, transporting the saliva in a cool box to the lab serial dilution from $10^{-1}-10^{-5}$ was done and then from $10^{-3}-10^{-5}$ were cultured in the Mitis Salivaris Bacitracin agar (HI Media) which was previously prepared as in al mizraqchi [25], simple identification to MS was done by gram stain, colony morphology, catalase test then counting the MS as in. [25] representing the result in cfu/ $\mathrm{ml}$ (colony forming unit). The SIgA was determined by ELISA kit (Demeditec, Germany) by following the manufacture instruction. Statistical analysis relies on SPSS program version 18. Data between the 3 groups were analyzed by Kruskal-Wallis, while between the two groups by MannWhitney test because the variables were not normally distributed.

Spearman's test was used to find out the correlation $\mathrm{P}$ value $(P<0.05)$, were considered as statistically significant. $(\mathrm{P}=0.000)$ highly significant relation, $(\mathrm{P}>0.05)$ nonsignificant.

\section{Result}

Table (1) demonstrate the relation between the viable count of MS and the ECC groups and gender, there was highly significant (HS) relation especially between the mild and the moderate and between the mild and severe but between the moderate and severe was not significant relation. The median value of the severe group was the highest and of the mild is the lowest. In the present study, investigating the MS group that had been cultured, in special media as mentioned before, the viable count of MS (mean, $\pm \mathrm{SD}$ ) was $(26.542, \pm 27.029$ ), (110.248, \pm 155.419$),(185.290, \pm 180.152)$ in mild, moderate, severe respectively, while the median was in the same order $(17.000,66.200,120.000)$ so we observe the increase with the MS count, the (mean, \pm SD) for $(\mathrm{dmft})$ values was for mild $(1.240, \pm .970)$, moderate $(11.440$, $\pm 2.815)$, severe $(12.720, \pm 3.234)$

Table (2) illustrates the salivary Immunoglobulin A statistically measured to the ECC groups and gender. in gender, the boys showed significant relation especially between the mild and severe while in the girls the relation was non-significant. The significant relation was between the mild and severe group. There was increase in the concentration of SIgA as the median value for the mild was the lowest and in the severe was the highest. The correlation between the MS count and the SIgA in the different ECC stages (mild, moderate, severe) was demonstrated in table (3), that showed a significant correlation between the viable count of MS and the SIgA in the total ECC groups.

Table 1: The viable count of MS in relation to the ECC groups and gender

\begin{tabular}{|c|c|c|c|c|c|c|c|c|c|c|}
\hline Vars. & Cat. & Group & $N$ & $\%$ & $M S$ count $\times 10^{4}$ & $\pm S D$ & Median & $* M R$ & Statistics & $* M C$ \\
\hline \multirow{8}{*}{ Gender } & \multirow{4}{*}{ Boys } & Mild & 8 & 20.51 & 11.949 & 6.596 & 15.000 & 24.38 & \multirow{3}{*}{$\begin{array}{c}X^{2}=2.420 \\
P=0.298\end{array}$} & \\
\hline & & Moderate & 16 & 41.03 & 129.606 & 186.065 & 69.450 & 17.72 & & \\
\hline & & Severe & 15 & 38.46 & 124.937 & 81.814 & 88.450 & 20.10 & & \\
\hline & & Total & 39 & 100 & 103.675 & 135.546 & 72.700 & & & \\
\hline & \multirow{4}{*}{ Girls } & Mild & 17 & 47.22 & 33.409 & 30.335 & 17.800 & 20.88 & \multirow{3}{*}{$\begin{array}{c}\mathrm{X}^{2}=2.103 \\
\mathrm{P}=0.349\end{array}$} & \\
\hline & & Moderate & 9 & 25.00 & 75.833 & 73.961 & 48.600 & 16.67 & & \\
\hline & & Severe & 10 & 27.78 & 275.820 & 246.894 & 192.500 & 16.10 & & \\
\hline & & Total & 36 & 100 & 111.351 & 168.372 & 52.675 & & & \\
\hline \multirow{3}{*}{\multicolumn{2}{|c|}{ Total }} & Mild & 25 & 33.33 & 26.542 & 27.029 & 17.000 & 20.52 & \multirow{3}{*}{$\begin{aligned} X^{2} & =29.323 \\
\mathbf{P} & =\mathbf{0 . 0 0 0}\end{aligned}$} & $* 1 X 2=0.006$ \\
\hline & & Moderate & 25 & 33.33 & 110.248 & 155.419 & 66.200 & 39.72 & & $\mathbf{1 X} 3=0.000$ \\
\hline & & Severe & 25 & 33.33 & 185.290 & 180.152 & 120.000 & 53.76 & & $2 \times 3=0.068$ \\
\hline \multicolumn{3}{|c|}{ Total } & 75 & 100 & 107.360 & 151.189 & 65.000 & & & \\
\hline
\end{tabular}

\section{Volume 6 Issue 7, July 2017 www.ijsr.net}




\section{International Journal of Science and Research (IJSR) ISSN (Online): 2319-7064}

Index Copernicus Value (2015): 78.96 | Impact Factor (2015): 6.391

Table 2: Salivary Immunoglobulin A in relation to the ECC groups and gender

\begin{tabular}{|c|c|c|c|c|c|c|c|c|c|c|}
\hline Vars. & Cat. & Group & $\mathrm{N}$ & $\%$ & Mean & $\pm \mathrm{SD}$ & Median & MR & Statistics & $\mathrm{MC}$ \\
\hline \multirow{8}{*}{ Gender } & \multirow{4}{*}{ Boys } & Mild & 8 & 20.51 & 42.302 & 24.367 & 40.334 & 9.63 & \multirow{4}{*}{$\begin{array}{c}X^{2}=9.650 \\
\mathbf{P}=\mathbf{0 . 0 0 8}\end{array}$} & \multirow{8}{*}{$\begin{array}{l}1 X 2=0.087 \\
1 X 3=0.006 \\
2 X 3=0.756\end{array}$} \\
\hline & & Moderate & 16 & 41.03 & 79.730 & 36.072 & 80.569 & 20.41 & & \\
\hline & & Severe & 15 & 38.46 & 135.066 & 98.772 & 110.537 & 25.10 & & \\
\hline & & Total & 39 & 100 & 93.335 & 74.370 & 71.259 & & & \\
\hline & \multirow{4}{*}{ Girls } & Mild & 17 & 47.22 & 94.905 & 115.036 & 66.269 & 14.29 & \multirow{4}{*}{$\begin{array}{c}X^{2}=5.168 \\
P=0.075\end{array}$} & \\
\hline & & Moderate & 9 & 25.00 & 112.358 & 74.498 & 94.550 & 22.72 & & \\
\hline & & Severe & 10 & 27.78 & 123.112 & 86.368 & 101.301 & 21.85 & & \\
\hline & & Total & 36 & 100 & 107.104 & 96.896 & 78.217 & & & \\
\hline \multirow{3}{*}{\multicolumn{2}{|c|}{ Total }} & Mild & 25 & 33.33 & 78.072 & 98.094 & 57.738 & 26.54 & \multirow{3}{*}{$\begin{aligned} X^{2} & =11.015 \\
\mathbf{P} & =\mathbf{0 . 0 0 4}\end{aligned}$} & \multirow{4}{*}{$\begin{array}{c}* * \\
1 \mathrm{X} 2=0.051 \\
\mathbf{1 X 3}=\mathbf{0 . 0 0 4} \\
2 \mathrm{X} 3=1.00\end{array}$} \\
\hline & & Moderate & 25 & 33.33 & 91.476 & 54.025 & 88.360 & 41.26 & & \\
\hline & & Severe & 25 & 33.33 & 130.284 & 92.325 & 101.301 & 46.20 & & \\
\hline \multicolumn{3}{|c|}{ Total } & 75 & 100 & 99.944 & 85.608 & 74.204 & & & \\
\hline
\end{tabular}

Table 3: The correlation between the viable count of MS in relation to study variables

\begin{tabular}{|c|c|c|c|}
\hline \multicolumn{3}{|c|}{ Group } & MS count \\
\hline \multirow{3}{*}{ Mild } & \multirow{3}{*}{$\operatorname{SIgA}$} & $\mathrm{R}$ & .027 \\
\hline & & \multirow{2}{*}{$\begin{array}{c}\mathrm{P}- \\
\text { value }\end{array}$} & .900 \\
\hline & & & NS \\
\hline \multirow{3}{*}{ Moderate } & \multirow{3}{*}{$\operatorname{SIg} \mathrm{A}$} & $\mathrm{R}$ & .213 \\
\hline & & \multirow{2}{*}{$\begin{array}{c}\mathrm{P}- \\
\text { value }\end{array}$} & .306 \\
\hline & & & NS \\
\hline \multirow{3}{*}{ Severe } & \multirow{3}{*}{ SIgA } & $\mathrm{R}$ & -.114 \\
\hline & & \multirow{2}{*}{$\begin{array}{c}\mathrm{P}- \\
\text { value }\end{array}$} & .589 \\
\hline & & & NS \\
\hline \multirow{3}{*}{ Total } & \multirow{3}{*}{$\operatorname{SIgA}$} & $\mathrm{R}$ & 0.288 \\
\hline & & \multirow{2}{*}{$\begin{array}{c}\mathrm{P}- \\
\text { value }\end{array}$} & 0.012 \\
\hline & & & S. \\
\hline
\end{tabular}

\section{Discussion}

Early childhood caries considered as a transmissible disease that is widely prevalent in the developed countries, often attributed to "sucrose-civilization- caries trinity", the increased intake of sweetened beverage which is one of the caries etiological factors besides time, susceptible host (teeth), and cariogenic bact., ECC caries development in deciduous teeth doesn't differ that much from the caries development in permanent teeth [26].

Saliva play an important role in the oral cavity by its immunological and non-immunological constituent which reflect a picture of the body secretion, the immunity in children developed with the age and being more susceptible to various microbiota and different antigens [27], [28].

The role of the MS bacteria in the initiation of caries had been studied by many researchers, [9], [25] MS group had the ability to surround itself by forming poly saccharide (PS) layer, which considered one of its virulent factors, that been converted to acids when lack of resources happens in the environment, also the ability of the bacteria in metabolizing the sugar to acid if there was a shift in the balanced environment toward the demineralization process [29]. One of the risk factors for the (ECC) progression is the presence of" Extracellular insoluble polysaccharides" in the plaque on the teeth, those found to be correlated with the increased consumption of sweetened beverage "solid sucrose" [30].
Different values of MS count in plaque and saliva was found in relation to the different stages of the caries, diet, and other types of involved bacteria [31],[32]. The higher count of MS bact.in early childhood will lead to higher DMF index at adulthood [33], so indicating the importance of monitoring the oral hygiene in childhood.

Klinke et al. [34] study the count of MS type and Lactobacillus before and after the treatment of decayed teeth in children with ECC, the result was a significant lower count of the bacteria after the treatment of the decayed teeth.

The present study results demonstrate the viable count of MS increase as the severity of the caries increase, indicating there is more inhabitant of MS species as the dental caries index (dmft) increase, although there was non-significant correlation between the viable count of MS in boys and girls group, but the study revealed a significant relation with the total groups.

When comparing the present study results with other studies, in considering the mild group relatively closer to the caries free groups as their mean dmft was (1.240, SD \pm .970), some have the same a findings significant correlation between viable count of MS and dental caries index [35],[36],[31],[32], others have the opposite [37] due to the difference in the criteria been used or methods or the sample collection.

Salivary Immunoglobulin A (SIgA) is the prevalent type in the salivary secretion, SIgA role in the oral cavity against different species of bacteria viruses, other types of microorganisms, by: bacterial adherence inhibition, neutralizing effect, agglutination, IgA presence in breast milk especially colostrum give further defense against microorganisms in the oral cavity in addition to the GIT [38], [13].

A systemic review done by da Silva Fidalgo et al. [38] concluding the higher level of SIgA in caries active groups so referring the cause to "Salivary IgA reflects a previous exposure of the host to cariogenic microorganisms"

The study results revealed the relation between the SIgA and the dental caries index, which is represented in table (2), statistical analyses of the relations between the groups illustrated a highly significant correlation between the mild

\section{Volume 6 Issue 7, July 2017 www.ijsr.net}




\section{International Journal of Science and Research (IJSR) \\ ISSN (Online): 2319-7064}

Index Copernicus Value (2015): 78.96 | Impact Factor (2015): 6.391

and severe type of ECC in the variables: in boys, and between the total groups.

The same concept was found in many studies as in the present article, relating higher levels of SIgA with the higher dental caries index (dmft, dmfs) and ECC cases, [39], [40], [41], [42], [43].

A controversy was found in research done by [44], [45]. In which Kuriakose et al. [44] found lower SIgA level in rampant caries children and higher in caries free children, relating its role in decreasing the caries in children. Also [45] Yassin studied the level of SIgA in caries free and caries active groups, stimulated saliva samples had been collected from children aged (7-10) years old, the caries active have lower level than caries free

Table (3) showed that there is a significant correlation $(\mathrm{p}<0.05)$ between MS count and the SIgA in the total groups $(\mathrm{P}=0.012)$ and non-significant correlation in MS count with each group as a variable, and table (1) and (2) showed there is an increase in the mean value between the groups from the lower caries to higher caries subjects, many authors have reached the same conclusion in their experiments like [15] [16], [17]. these results didn't relate the $\operatorname{SIgA}$ as an important immune component in saliva against SM, associating the higher levels of SIgA in saliva to the immune response, which has been induced by the presence MS species, another explanation could be due to counting the total SIgA not the specific S. mutans SIgA levels.

Thaweboon et al. [15] investigated the level of MS count and SIgA, pH, flow rates, and candida in kids (5-10Y) having (rampant caries) and caries free groups, estimating the SIgA level by ELIZA kit, the increased level of SIgA with the increased level of SM count hypothesizing that increased levels of salivary SIgA may reflect a previous exposure of the host to cariogenic bact.

Parisotto et al. [16] examine the level of MS, LB microorganism and the level of SIgA, then one year later examining the same variables, in (3-4) years old children revealing, in the first measurement the caries active have higher level of SIgA and MS count than caries free, the one year later examination reveal an increase in the MS count especially in the caries active group, the SIgA level increased with age also the increased number of the MS count may induce the immune system to secrete more immunoglobulins.

\section{References}

[1] Çolak H, Dülgergil ÇT, Dalli M, Hamidi MM. Early childhood caries update: A review of causes, diagnoses, and treatments. Journal of Natural Science, Biology and Medicine. 2013;4(1):29.

[2] Fontana M, Jackson R, Eckert G, Swigonski N, Chin J, Zandona $\mathrm{AF}$, et al. Identification of caries risk factors in toddlers. J Dent Res. 2011;90(2):209-14.

[3] Kühnisch J, Ekstrand K, Pretty I, Twetman S, Van Loveren C, Gizani S, et al. Best clinical practice guidance for management of early caries lesions in children and young adults: an EAPD policy document. European Archives of Paediatric Dentistry. 2016;17(1):3-12.

[4] AAPD. Policy on early childhood caries (ECC)classifications, consequences and preventive strategies. 2014. Reference Manual v36; no. 6. 2014/2015. 50-12. 2015.

[5] Ripa LW. Nursing caries: a comprehensive review. Pediatr Dent. 1988;10(4):268-82.

[6] Ismail AI, Sohn W. A systematic review of clinical diagnostic criteria of early childhood caries. Journal of public health dentistry. 1999;59(3):171-91.

[7] Duggal M, Cameron A, Toumba J. Paediatric dentistry at a glance: John Wiley \& Sons; 2012.

[8] Mattos-Graner RO, Klein MI, Smith DJ. Lessons learned from clinical studies: roles of mutans streptococci in the pathogenesis of dental caries Current Oral Health Reports. 2014;1(1):70-8.

[9] Ma C, Chen F, Zhang Y, Sun X, Tong P, Si Y, et al. Comparison of oral microbial profiles between children with severe early childhood caries and caries-free children using the human oral microbe identification microarray. PloS one. 2015;10(3):e0122075.

[10] Edgar WM. Saliva: its secretion, composition and functions. Br Dent J. 1992;172(8):305-12.

[11] Humphrey SP, Williamson RT. A review of saliva: normal composition, flow, and function. The Journal of prosthetic dentistry. 2001;85(2):162-9.

[12] de Almeida PDV, Gregio A, Machado M, De Lima A, Azevedo LR. Saliva composition and functions: a comprehensive review. J Contemp Dent Pract. 2008;9(3):72-80.

[13] Gao X, Jiang S, Koh D, Hsu C-YS. Salivary biomarkers for dental caries. Periodontology 2000. 2016;70(1):12841.

[14] Axelsson P. Diagnosis and risk prediction of dental caries. Illinoise Quintessence: Pub. 2000:55-76.

[15] Thaweboon S, Thaweboon B, Nakornchai S, Jitmaitree S. Salivary secretory $\operatorname{IgA}, \mathrm{pH}$, flow rates, mutans streptococci and Candida in children with rampant caries. 2008.

[16] Parisotto T, King W, Duque C, Mattos-Graner R, Steiner-Oliveira C, Nobre-Dos-Santos M, et al. Immunological and microbiologic changes during caries development in young children. Caries research. 2011;45(4):377-85.

[17] Yang Y, Li Y, Lin Y, Du M, Zhang P, Fan M. Comparison of immunological and microbiological characteristics in children and the elderly with or without dental caries. European journal of oral sciences. 2015;123(2):80-7.

[18] Chawda JG, Chaduvula N, Patel HR, Jain SS, Lala AK. Salivary SIgA and dental caries activity. Indian Pediatrics. 2011;48(9):719.

[19] Heba NY. Comparison of Immunoglobulin IgA Level in the Stimulated Saliva of Caries-Free and CariesActive Children Aged 7-10 Years. Journal of baghdad college of dentistry بغداد الاسنان طب كلية مجلة. 2016;28(3):155-8.

[20] WHO. Oral Health Surveys basic methods. 4thed. World Health Organization, Geneva, Switzerland, 1997. 


\section{International Journal of Science and Research (IJSR) \\ ISSN (Online): 2319-7064}

Index Copernicus Value (2015): 78.96 Impact Factor (2015): 6.391

[21] Wyne AH. Early childhood caries: nomenclature and case definition. Community dentistry and oral epidemiology. 1999;27(5):313-5.

[22] CDC growth Charts. Unit state. National Center for health statistics in collaboration with the National Center for Chronic Disease Prevention and Health Promotion, 30 may 2000

[23] WHO. Oral Health Surveys basic methods. 3rd ed. World Health Organization, Geneva, Switzerland, 1987.

[24] Navazesh M. Methods for collecting saliva. Annals of the New York Academy of Sciences. 1993;694(1):72-7.

[25] Al-Mizrakchi A. Adherence of Mutans Streptococci on Teeth Surfaces. Microbiological and Biochemical Studies: Ph. D. thesis, Al-Mustansiriya University, Baghdad; 1998.

[26] Fontana M, Young DA, Wolff MS, Pitts NB, Longbottom C. Defining dental caries for 2010 and beyond. Dental Clinics of North America. 2010;54(3):423-40.

[27] Brandtzaeg P. Current understanding of gastrointestinal immunoregulation and its relation to food allergy. Annals of the New York Academy of Sciences. 2002;964(1):13-45.

[28] Weemaes C, Klasen I, Göertz J, Beldhuis-Valkis M, Olafsson O, Haraldsson A. Development of immunoglobulin A in infancy and childhood. Scandinavian journal of immunology. 2003;58(6):6428.

[29] Seow WK. Biological mechanisms of early childhood caries. Community dentistry and oral epidemiology. 1998;26(S1):8-27.

[30] Parisotto TM, Stipp R, Rodrigues LKA, Mattos-Graner RO, Costa LS, Nobre-dos-Santos M. Can insoluble polysaccharide concentration in dental plaque, sugar exposure and cariogenic microorganisms predict early childhood caries? A follow-up study. Archives of Oral Biology. 2015;60(8):1091-7.

[31] Tanner ACR, Mathney JMJ, Kent RL, Chalmers NI, Hughes CV, Loo CY, et al. Cultivable Anaerobic Microbiota of Severe Early Childhood Caries. Journal of Clinical Microbiology. 2011;49(4):1464-74.

[32] Gross EL, Beall CJ, Kutsch SR, Firestone ND, Leys EJ, Griffen AL. Beyond Streptococcus mutans: Dental Caries Onset Linked to Multiple Species by $16 \mathrm{~S}$ rRNA Community Analysis. PLOS ONE. 2012;7(10):e47722.

[33] Köhler B, Andréen I. Mutans Streptococci and Caries Prevalence in Children after Early Maternal Caries Prevention: A Follow-Up at 19 Years of Age 2012.

[34] Klinke T, Urban M, Lück C, Hannig C, Kuhn M, Krämer N. Changes in Candida spp., mutans streptococci and lactobacilli following treatment of early childhood caries: a 1-year follow-up. Caries research. 2014;48(1):24-31.

[35] Begzati A, Berisha M, Meqa K. Early childhood caries in preschool children of Kosovo - a serious public health problem. BMC Public Health. 2010;10(1):788.

[36] Al-Bayati YA. Salivary streptococcus mutans and lactobacilli in relation to rampant caries pattern among children. J Bagh College Dentistry2011.

[37] Aas JA, Griffen AL, Dardis SR, Lee AM, Olsen I, Dewhirst FE, et al. Bacteria of dental caries in primary and permanent teeth in children and young adults. Journal of clinical microbiology. 2008;46(4):1407-17.

[38] da Silva Fidalgo TK, Freitas-Fernandes LB, Ammari M, Mattos CT, de Souza IPR, Maia LC. The relationship between unspecific s-IgA and dental caries: A systematic review and meta-analysis. Journal of dentistry. 2014;42(11):1372-81.

[39] Gonçalves de Farias D, Barreto Bezerra AC. Salivary antibodies, amylase and protein from children with early childhood caries. Clinical Oral Investigations. 2003;7(3):154-7.

[40] Bagherian A, Jafarzadeh A, Rezaeian M, Ahmadi S, Rezaity MT. Comparison of the salivary immunoglobulin concentration levels between children with early childhood caries and caries-free children. Iranian Journal of Immunology. 2008;5(4):217.

[41] Ranadheer E, Nayak UA, Reddy NV, Rao VAP. The relationship between salivary IgA levels and dental caries in children. Journal of Indian Society of Pedodontics and Preventive Dentistry. 2011;29(2):106.

[42] Bagherian A, Asadikaram G. Comparison of some salivary characteristics between children with and without early childhood caries. Indian Journal of Dental Research. 2012;23(5):628-32.

[43] Castro RJ, Herrera R, Giacaman RA. Salivary protein characteristics from saliva of carious lesion-free and high caries adults. Acta Odontológica Latinoamericana. 2016;29(2):178-85.

[44] Kuriakose S, Prasannan M, Remya K, Kurian J, Sreejith K. Prevalence of early childhood caries among preschool children in Trivandrum and its association with various risk factors. Journal of Indian Society of Pedodontics and Preventive Dentistry. 2013;31(2):6973.

[45] 1Yassin HN. Comparison of Immunoglobulin IgA Level in the Stimulated Saliva of Caries-Free and CariesActive Children Aged 7-10 Years. Journal of Baghdad College of Dentistry. 2016(3):155-8\% V 28. 